\title{
Proximity fed Broadband Microstrip Antennas
}

\author{
Amit A. Deshmukh \\ EXTC, DJSCOE \\ Vile - Parle (W), \\ Mumbai, India
}

\author{
Apurva A. Joshi \\ EXTC, DJSCOE \\ Vile - Parle (W), \\ Mumbai, India
}

\author{
Ankita R. Jain \\ EXTC, DJSCOE \\ Vile - Parle (W), \\ Mumbai, India
}

\author{
Tejal A. Tirodkar \\ EXTC, DJSCOE \\ Vile - Parle (W), \\ Mumbai, India
}

\begin{abstract}
The broadband microstrip antenna is realized by fabricating the patch on lower dielectric constant thicker substrate in conjunction with proximity feeding technique. Using thicker substrates, a formulation for an edge extension length and design guidelines for strip dimensions in proximity fed broadband antennas, are not available. In this paper, first by designing suspended rectangular and circular microstrip antennas on different substrate thickness and at various frequencies in 800 to $6000 \mathrm{MHz}$ frequency band, graphs for an edge extension length are developed. Using them an edge extension length at given frequency and substrate thickness is calculated. The suspended patches were further designed using edge extension length graphs which give closer result with the desired frequency. Further by using proposed equations, proximity fed microstrip antennas were optimized at various frequencies in 800 to $6000 \mathrm{MHz}$ frequency band. Using these optimized designs, a formulation for coupling strip parameters is proposed. By using proposed formulations for edge extension length and strip parameters, proximity fed antennas were re-designed at different frequencies in 800 to $6000 \mathrm{MHz}$ frequency band. In all the configurations, broadband response with formation of loop inside VSWR $=2$ circle is obtained. Also by using the proposed formulation, design procedure for proximity fed U-slot cut rectangular microstrip antenna is explained. The U-slot cut antenna gives bandwidth of more than $450 \mathrm{MHz}$ at center frequency of around $1000 \mathrm{MHz}$. The proposed formulations can be used to design broadband antennas using thicker substrate at any given frequency.
\end{abstract}

\section{Keywords}

Rectangular microstrip antenna, Circular Microstrip Antenna, Equilateral triangular microstrip antenna, Edge extension length, Proximity feeding, Broadband microstrip antenna

\section{INTRODUCTION}

The simplest method to realize broadband microstrip antenna (MSA) is by fabricating the patch on lower dielectric constant thicker substrate $[1,2]$. The thicker substrate reduces the quality factor of the cavity below the patch to realize larger bandwidth (BW). In most of the reported designs, radiating patch is suspended in air thereby realizing dielectric constant of unity. While calculating patch length at given frequency, an additional length due to the fringing field extension towards the open circuit edges of the patch is added. For thinner substrates $\left(\mathrm{h}<0.04 \lambda_{0}\right.$ ), formulation for an edge extension length is available. However for thicker substrates (h > $0.05 \lambda_{0}$ ) the formulation is not available. Further while designing broadband MSA for substrate thickness more than $0.05 \lambda_{0}$, antenna BW is limited by the feed probe inductance. In those substrates, a simpler proximity feeding technique is used [3]. In this technique, radiating patch is fed using the coupling strip which is either placed below or in the plane of the patch. A larger BW is realized due to electromagnetic coupling between the patch mode and the strip. This method yields broader BW for thickness more than $0.06 \lambda_{0}$. The BW of MSA is also increased by cutting a slot inside the patch [4 8]. Further increase in the BW of slot cut MSA is realized by using proximity feeding technique [9]. In proximity feeding method, for the given patch and strip substrate thickness, design parameters are, the strip dimensions and its position below or in the plane of the patch. In the available literature on proximity feeding, the design guidelines for given substrate thickness and operating frequency are not available.

In this paper, design formulations for broadband proximity fed MSAs on thicker substrates are proposed. First by designing rectangular MSA (RMSA) and circular MSA (CMSA) at a given frequency and for different substrate thickness in 800 to $6000 \mathrm{MHz}$ frequency band, plots for an edge extension length against substrate thickness are developed. Using them an edge extension length at any given frequency and substrate thickness is calculated. By using the proposed graphs, patch was re-designed at different frequencies in the above frequency band. It gives patch resonance frequency at nearly the same desired value with an error less than $2 \%$. Further broadband proximity fed RMSA, CMSA and equilateral triangular MSA (ETMSA) were designed at different frequencies in the 800 to $6000 \mathrm{MHz}$ frequency band. Using their optimum designs, the formulations for strip dimensions and its position below the patch for the given patch substrate thickness is proposed. Using edge extensions graphs and the formulation for strip dimensions, proximity fed RMSA, CMSA and ETMSA were re-designed at different frequencies in 800 to $6000 \mathrm{MHz}$ frequency band. A broadband response with the formation of loop inside the VSWR $=2$ circle is obtained. Using proximity fed formulations, a detail design procedure for proximity fed U-slot cut RMSA is also presented. It gives broadband response with BW of more than $450 \mathrm{MHz}(>45 \%)$. The above study was carried out using IE3D software followed by experimental verifications [10]. In IE3D simulations an infinite ground plane was used. In measurements the antennas were fabricated using the copper plate having finite thickness and were supported in air using the foam spacer support placed towards the antenna corners. The antenna was fed using $\mathrm{N}$-type connector of $0.32 \mathrm{~cm}$ inner wire diameter. At all the frequencies, measurements were carried out using $\mathrm{R} \& \mathrm{~S}$ vector network analyzer ( $\mathrm{ZVH} 8$ model) using finite square ground plane of side length $100 \mathrm{~cm}$. This larger ground plane simulates the effect of infinite ground plane. The radiation pattern was measured in minimum reflection surroundings with required minimum far field distance between reference antenna and antenna under test [11]. The antenna gain was measured using three antenna method [11]. The proposed 
formulations can be used to design proximity fed antennas on thicker substrates at any given frequency.

\section{EDGE EXTENSION LENGTHS FOR RMSA AND CMSA}

The RMSA suspended in air substrate of thickness ' $h$ ' is shown in Fig. 1 $(a, b)$. To model the fringing field extension length $(\Delta \mathrm{l})$, RMSA was designed at different frequencies. At each frequency patch was designed for different substrate thickness. At all the frequencies substrate thickness is taken to be less than $0.1 \lambda_{0}$. At $900 \mathrm{MHz}$, patch length is calculated by using equation (1). Using this value of $\mathrm{L}_{\mathrm{e}}$ as patch length and with $\mathrm{W}=1.2 \mathrm{~L}_{\mathrm{e}}$, the antenna was simulated using IE3D software and the peak in its resonance curve is observed. If the peak is not present at $900 \mathrm{MHz}$, the patch length was changed and the simulation was again carried out. For every iteration, patch width is taken to be 1.2 times the patch length. This procedure is repeated until the peak in the resonance curve is present at around $900 \mathrm{MHz}$. This simulated value of length $(\mathrm{L})$ is noted and the fringing length $(\Delta \mathrm{l})$ is calculated by using equation (2). This procedure is repeated for different values of substrate thickness and for different frequencies and they are plotted in Figs. 1(c) and 2(a). The graphs show $\Delta \mathrm{l}$ in terms of substrate thickness (h).

$$
\mathrm{L}_{\mathrm{e}}=\mathrm{c} / 2 \mathrm{f}_{\mathrm{r}}
$$

where, $\mathrm{c}=$ velocity of light $=3 \times 10^{8}(\mathrm{~m} / \mathrm{s})$

$\Delta \mathrm{l}=\left(\mathrm{L}_{\mathrm{e}}-\mathrm{L}\right) / 2$

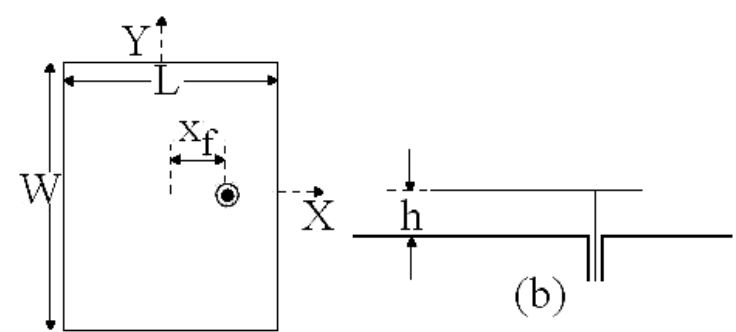

(a)

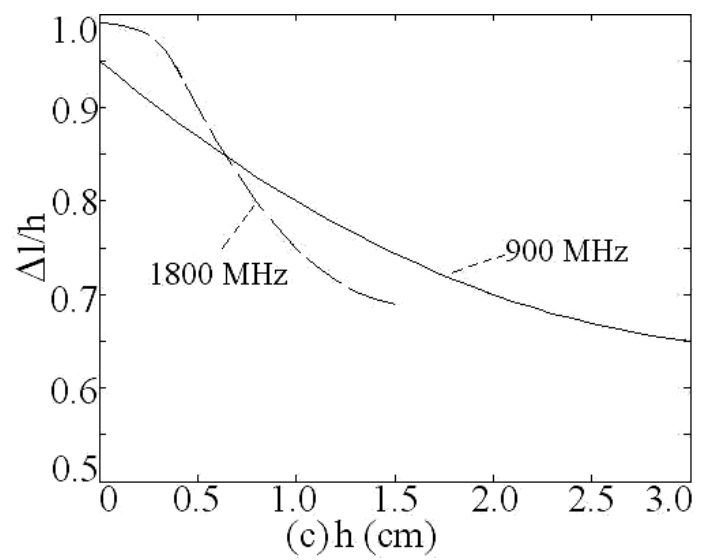

Fig. 1 (a) Top and (b) side views of RMSA, and its (c) edge extension plots against substrate thickness

For larger substrate thickness edge extension length due to fringing fields reduces with the frequency. Using the above procedure, an edge extension length for different patch widths at given frequency is calculated and it is plotted in Fig. 2(b, c). For given patch length, with decrease in 'W', its resonance frequency increases. Hence for same resonance frequency, patch length is increased, which reduces an edge extension length.

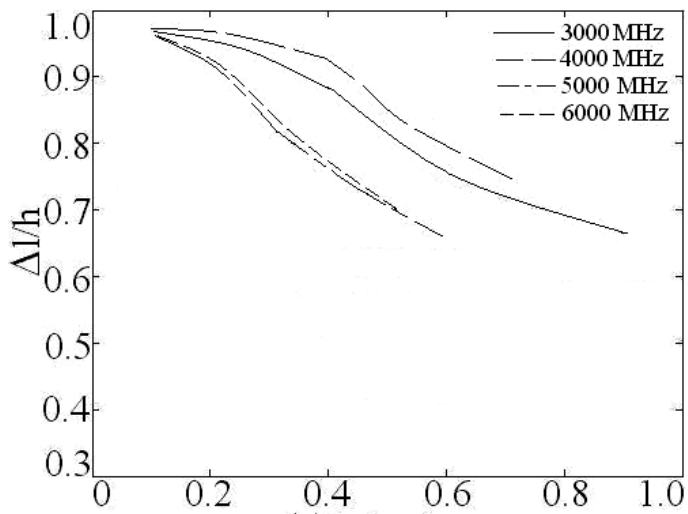

(a)h $(\mathrm{cm})$

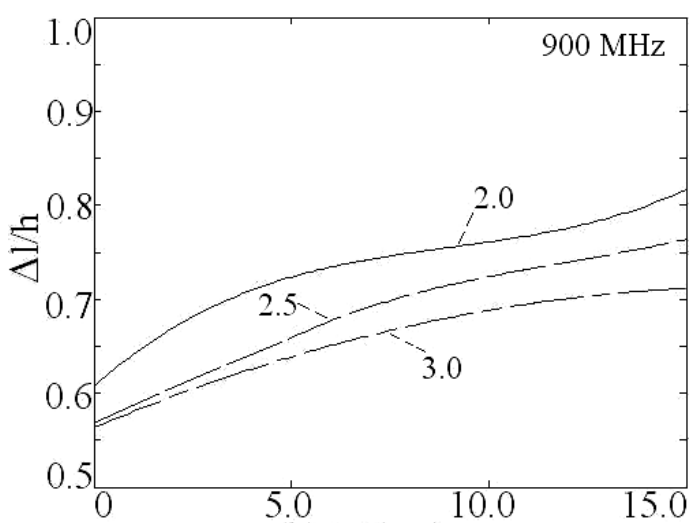

(b) W (cm)

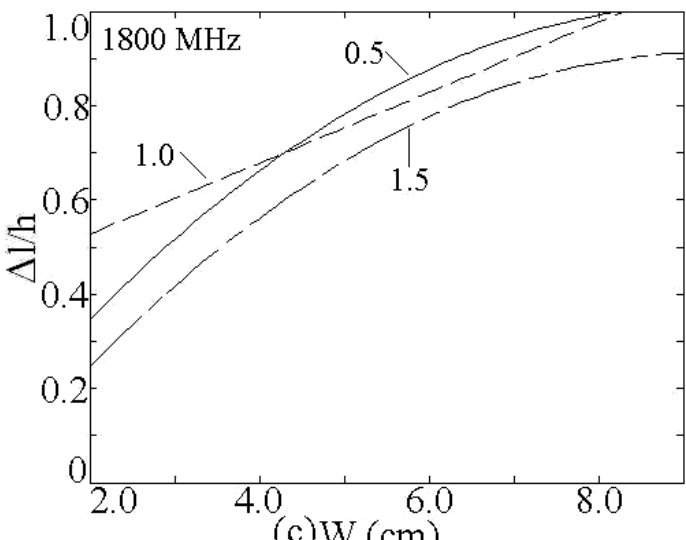

Fig. 2 Edge extension plots against (a) substrate thickness and $(b, c)$ for different widths for RMSA

Further by using these graphs, RMSA is re-designed at 1200 $\mathrm{MHz}, 3500 \mathrm{MHz}$ and $5500 \mathrm{MHz}$. At $1200 \mathrm{MHz}$, for edge extension length, plot for $900 \mathrm{MHz}$ are used. The substrate thickness $\mathrm{h}=2.0 \mathrm{~cm}\left(0.08 \lambda_{0}\right)$ is selected. For this value, $\Delta \mathrm{l} / \mathrm{h}$ is 0.7 , which gives $\Delta \mathrm{l}=1.4 \mathrm{~cm}$. The value of $\mathrm{L}_{\mathrm{e}}$ calculated by using equation (1) is $12.5 \mathrm{~cm}$. Further, RMSA is simulated by using $\mathrm{L}=(12.5-2.8)=9.7 \mathrm{~cm}$ and $\mathrm{W}=1.2 \mathrm{~L}$. This gives peak in the resonance curve at $1182 \mathrm{MHz}$ which is very close to the desired value (error of $1.5 \%$ ). At $3500 \mathrm{MHz}$, the value of $\Delta \mathrm{l} / \mathrm{L}$ is calculated as its average value as given by 3000 and $4000 \mathrm{MHz}$ graph. It is found to be 0.74 . The substrate thickness of $h=0.7 \mathrm{~cm}\left(0.08 \lambda_{0}\right)$ is selected. The patch length and width as calculated by using equations (1) and (2) are 3.3 
$\mathrm{cm}$ and $4.0 \mathrm{~cm}$, respectively. For this dimension, peak in the resonance curve is present at $3452 \mathrm{MHz}$ which is close to the desired frequency with an error of $1.37 \%$. At $5500 \mathrm{MHz}$, for substrate thickness of $\mathrm{h}=0.45 \mathrm{~cm}\left(0.08 \lambda_{0}\right)$ the patch dimension calculated by using above procedure is, $\mathrm{L}=2.1 \mathrm{~cm}$ and $\mathrm{W}=2.5 \mathrm{~cm}$. This simulated and peak in the resonance curve is present at $5433 \mathrm{MHz}$ which is also close to the desired value with error of $1.2 \%$. Thus the proposed graphs can be used to design the RMSA at any given frequency.

Similar study is carried out for CMSA as shown in Fig. $3(\mathrm{a}, \mathrm{b})$. The resonance frequency of CMSA is calculated by using equation (3). For given substrate thickness, using effective dielectric constant $\left(\varepsilon_{\mathrm{re}}\right)$ of unity and for fundamental $\mathrm{TM}_{11}$ mode $\left(\mathrm{K}_{\mathrm{mn}}=1.84118\right)$, patch radius $\left(\mathrm{a}_{\mathrm{e}}\right)$ is calculated. This is simulated using IE3D software and peak in the resonance curve is observed. If it is not present at desired frequency, by changing the patch radius, simulation is repeated until the peak is obtained at desired frequency. This value of new patch radius $\left(a_{1}\right)$ is noted and the extension in patch radius is calculated by using equation (4). This procedure is repeated for different frequencies and substrate thickness and they are plotted in Fig. 3(c, d). Similar to RMSA, an edge extension length reduces with substrate thickness. Using these graphs, CMSA is designed at 1200 MHz. The value of $a_{e}$ obtained using equation (3) is $7.33 \mathrm{~cm}$. Using graphs for $900 \mathrm{MHz}$, for $\mathrm{h}=2.0 \mathrm{~cm}\left(0.08 \lambda_{0}\right), \Delta \mathrm{a} / \mathrm{h}$ was found to be 0.85 , which gives $\mathrm{a}_{1}=5.63 \mathrm{~cm}$ by using equation (4). This is simulated and it gives peak in the resonance curve at $1191 \mathrm{MHz}$ which is very close to desired value with an error of $0.75 \%$. Further the CMSA is designed at $3500 \mathrm{MHz}$. The $\mathrm{a}_{\mathrm{e}}$ calculated using equation (3) is $2.52 \mathrm{~cm}$. Using graphs for $3000 \mathrm{MHz}$, for $\mathrm{h}=0.7 \mathrm{~cm}\left(0.08 \lambda_{0}\right), \Delta \mathrm{a} / \mathrm{h}$ was found to be 0.825 , which gives $a_{1}=1.94 \mathrm{~cm}$ by using equation (4). This is simulated and the peak in the resonance curve was observed at $3484 \mathrm{MHz}$ which is very close to desired value (error of $0.5 \%$ ). Thus the proposed graphs can be used to design CMSA on thicker substrates and at desired frequency.

$\mathrm{f}_{\mathrm{r}}=\mathrm{K}_{\mathrm{mn}} \mathrm{c} / 2 \mathrm{a} \pi \sqrt{\varepsilon_{\mathrm{re}}}$

$\Delta \mathrm{a}=\mathrm{a}_{\mathrm{e}}-\mathrm{a}_{1}$

\section{PROXIMITY FED MSAs}

The proximity fed RMSA is shown in Fig. 3(e, f). The coupling strip is placed below the patch. This configuration is optimized for broader BW at $900 \mathrm{MHz}, 1800 \mathrm{MHz}$ and 5500 MHz. At each frequency, substrate thickness for patch $\left(h_{1}\right)$ is selected such that it gives $h_{1}=0.08 \lambda_{0}$. Using the above edge extension graphs, RMSA dimensions are selected such that it resonates in $\mathrm{TM}_{10}$ mode. At lower frequencies i.e. below 2500 $\mathrm{MHz}$, the thickness of coupling strip $\left(\mathrm{h}_{2}\right)$ is selected such that it is placed $0.2 \mathrm{~cm}$ below the patch whereas for frequency > $3000 \mathrm{MHz}$, it is placed $0.1 \mathrm{~cm}$ below the patch. At each frequency, optimum BW is obtained by using the parametric study for variations in strip dimensions and its position below the patch. By optimizing these parameters, broader BW at each frequency is obtained. At $900 \mathrm{MHz}$, simulated $\mathrm{BW}$ is $300 \mathrm{MHz}$. The response is experimentally verified and the measured BW is $289 \mathrm{MHz}$. At $1800 \mathrm{MHz}$, the simulated BW is $485 \mathrm{MHz}$ whereas the measured $\mathrm{BW}$ is $470 \mathrm{MHz}$. The simulated $\mathrm{BW}$ at $5500 \mathrm{MHz}$ is $1070 \mathrm{MHz}$ whereas the measured BW is $1002 \mathrm{MHz}$. The design parameter dimensions at above frequencies are given in Table 1.

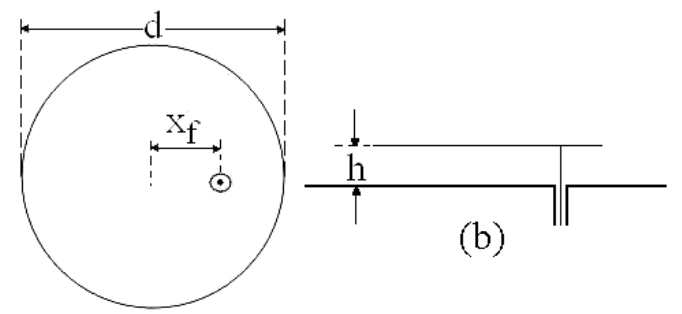

(a)

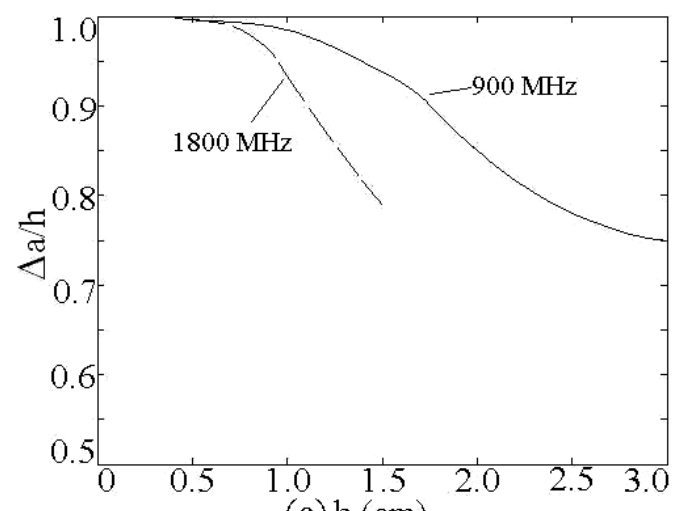

(c) h (cm)

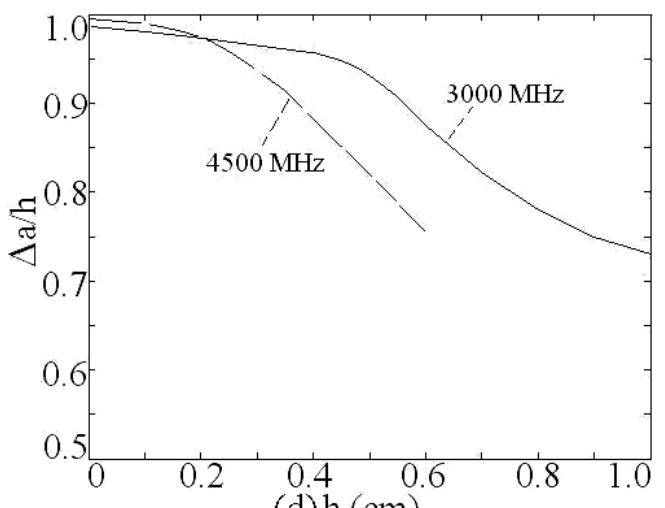

(d) h $(\mathrm{cm})$

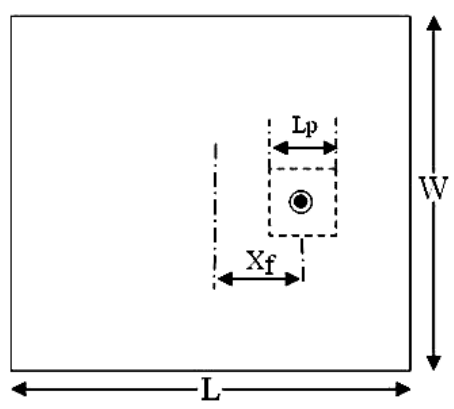

(e)

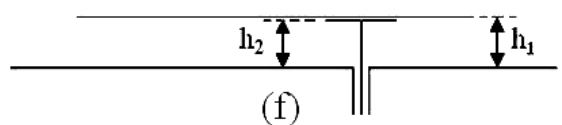

Fig. 3 (a) Top and (b) side views of CMSA and its (c, d) variation in edge extension length against substrate thickness, (e) top and (f) side views of proximity fed RMSA

Table 1: Design parameters for proximity fed RMSA \begin{tabular}{|l|l|l|l|}
\hline Parameter & $900 \mathrm{MHz}$ & $1800 \mathrm{MHz}$ & $5500 \mathrm{MHz}$ \\
\hline
\end{tabular} 


\begin{tabular}{|c|c|c|c|}
\hline $\mathrm{X}_{\mathrm{f}}$ & 3.5 & 1.67 & 0.6 \\
\hline $\mathrm{L}_{\mathrm{p}}$ & 2.0 & 1.2 & 0.4 \\
\hline $\mathrm{h}_{1}$ & 2.8 & 1.4 & 0.5 \\
\hline
\end{tabular}

By observing the above parameters, formulation for strip parameters at any given frequencies are, $\mathrm{h}_{1}=0.08 \lambda_{0}, \mathrm{X}_{\mathrm{f}}=$ $0.11 \lambda_{0}$, and $\mathrm{L}_{\mathrm{p}}=0.075 \lambda_{0}$. Using these parameters the proximity fed RMSAs is designed at $1200 \mathrm{MHz}$ and 3500 MHz. As discussed above, patch dimension at $1200 \mathrm{MHz}$ are, $\mathrm{L}=9.7 \mathrm{~cm}, \mathrm{~W}=11.6 \mathrm{~cm}$. The strip of dimension $\mathrm{L}_{\mathrm{p}}=1.87$ $\mathrm{cm}$ is placed at $\mathrm{x}_{\mathrm{f}}=2.75 \mathrm{~cm}$ at substrate thickness of $\mathrm{h}_{2}=1.8$ $\mathrm{cm}$. This results in formation of loop inside the VSWR $=2$ circle as shown in Fig. 4(a). The simulated BW is $232 \mathrm{MHz}$ whereas the measured $\mathrm{BW}$ is $224 \mathrm{MHz}$. The various design parameters at $3500 \mathrm{MHz}$, obtained using above formulations are, $\mathrm{h}_{1}=0.7 \mathrm{~cm}, \mathrm{~h}_{2}=0.6 \mathrm{~cm}, \mathrm{~L}=3.3 \mathrm{~cm}, \mathrm{~W}=4.0 \mathrm{~cm}, \mathrm{~L}_{\mathrm{p}}=$ $0.64 \mathrm{~cm}, \mathrm{x}_{\mathrm{f}}=0.94 \mathrm{~cm}$. It gives simulated $\mathrm{BW}$ of $936 \mathrm{MHz}$ whereas the measured BW is $964 \mathrm{MHz}$ as shown in Fig. 4(b).

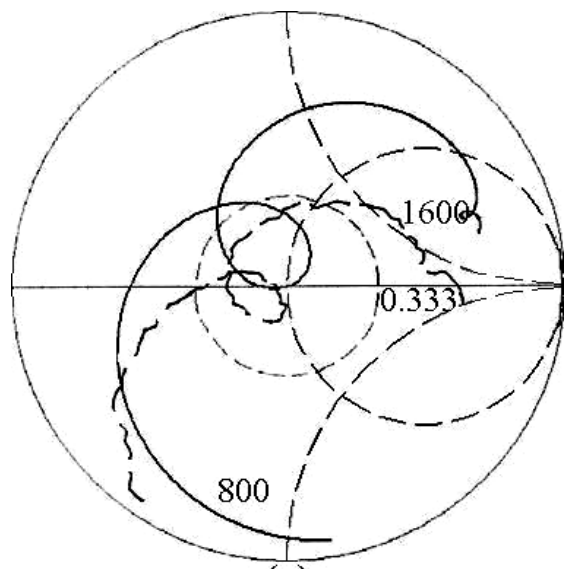

(a)

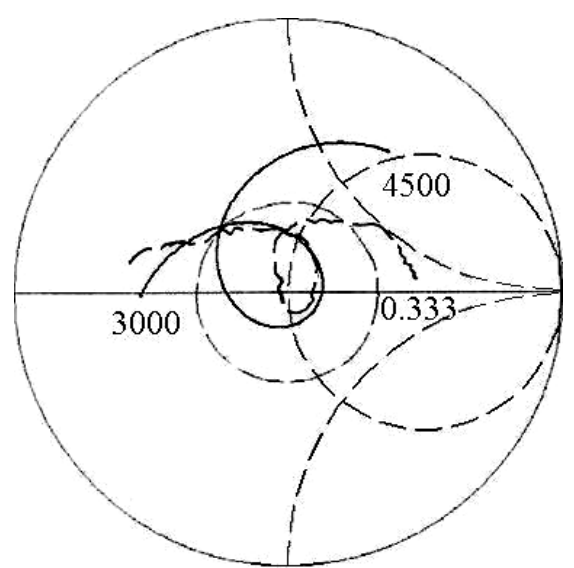

(b)

Fig. 4 Input impedance plots for proximity fed RMSA at (a) $1200 \mathrm{MHz}$ and (b) $3500 \mathrm{MHz},(-)$ simulated, $(--)$ measured

Similarly the design guidelines were formulated for proximity fed RMSA with the coupling strip placed inside the patch as shown in Fig. 5. The design formulation for the same is given in Table 2. Using these formulations the RMSA was designed at $2500 \mathrm{MHz}$ and its simulated and measured $\mathrm{BW}$ is, 450 $\mathrm{MHz}(19.7 \%)$ and $458 \mathrm{MHz}$ (19.9\%), respectively.

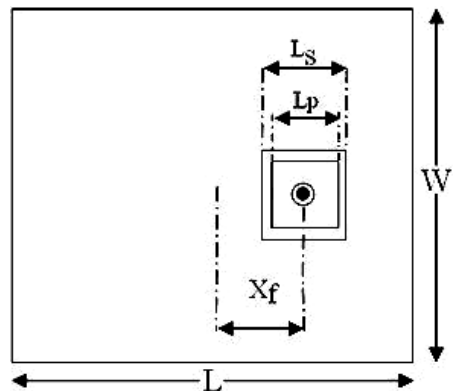

Fig. 5 Proximity fed RMSA with strip inside the patch

Table 2: Design parameters for proximity fed RMSA with

\begin{tabular}{|c|c|c|c|c|}
\hline $\begin{array}{c}\text { strip inside the patch } \\
(\mathrm{MHz})\end{array}$ & $\begin{array}{c}\mathrm{h} \\
(\mathrm{cm})\end{array}$ & $\begin{array}{c}\mathrm{L}_{\mathrm{s}} \\
(\mathrm{cm})\end{array}$ & $\begin{array}{c}\mathrm{X}_{\mathrm{f}} \\
(\mathrm{cm})\end{array}$ & $\begin{array}{c}\mathrm{L}_{\mathrm{p}} \\
(\mathrm{cm})\end{array}$ \\
\hline 900 & 3.0 & 3.4 & 3.8 & 2.8 \\
\hline 1800 & 1.5 & 1.7 & 1.9 & 1.4 \\
\hline 3000 & 0.9 & 1.0 & 1.1 & 0.84 \\
\hline 5000 & 0.54 & 0.6 & 0.7 & 0.5 \\
\hline 8000 & 0.34 & 0.38 & 0.43 & 0.32 \\
\hline $\begin{array}{c}\text { In terms of } \\
\lambda_{0}\end{array}$ & $0.09 \lambda_{0}$ & $0.102 \lambda_{0}$ & $0.114 \lambda_{0}$ & $0.084 \lambda_{0}$ \\
\hline
\end{tabular}

Similarly by using parametric study, proximity fed CMSA as shown in Fig. 6(a, b) is optimized for BW at different frequencies in 800 to $6000 \mathrm{MHz}$ frequency band. The optimized results and various optimized parameters are shown in Table 3 and 4, respectively. Using them design guideline for proximity fed CMSA are formulated as, $\mathrm{X}_{\mathrm{f}}=0.102 \lambda_{0}$ and $\mathrm{L}_{\mathrm{p}}=0.07 \lambda_{0}$.

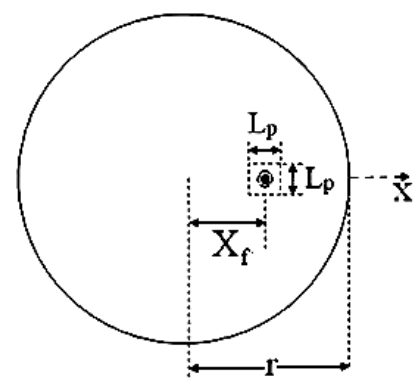

(a)

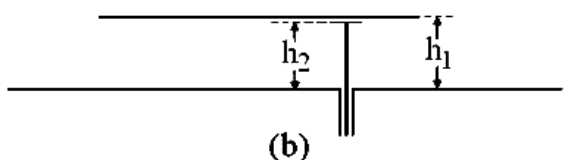

Fig. 6 (a) Top and (b) side views of proximity fed CMSA

Table 3: Design parameters for proximity fed CMSA

\begin{tabular}{|c|c|c|c|}
\hline Parameter & $\begin{array}{c}900 \\
\mathrm{MHz}\end{array}$ & $\begin{array}{c}2000 \\
\mathrm{MHz}\end{array}$ & $\begin{array}{c}5000 \\
\mathrm{MHz}\end{array}$ \\
\hline $\mathrm{X}_{\mathrm{f}},(\mathrm{cm})$ & 3.4 & 1.53 & 0.65 \\
\hline $\mathrm{L}_{\mathrm{p}},(\mathrm{cm})$ & 2.2 & 1.2 & 0.5 \\
\hline $\mathrm{h}_{1},(\mathrm{~cm})$ & 2.7 & 1.2 & 0.5 \\
\hline
\end{tabular}

Table 4: Results for proximity fed CMSA

\begin{tabular}{|c|c|c|}
\hline Frequency & $\begin{array}{c}\text { Simulated BW, } \\
\text { MHz, \% }\end{array}$ & $\begin{array}{c}\text { Measured BW, } \\
\text { MHz, \% }\end{array}$ \\
\hline $900 \mathrm{MHz}$ & $261,28.1$ & $272,28.9$ \\
\hline $2000 \mathrm{MHz}$ & $443,21.9$ & $456,22.2$ \\
\hline $5000 \mathrm{MHz}$ & $1526,28.5$ & $1490,27.0$ \\
\hline
\end{tabular}


Using these formulations and above edge extension plots, the proximity fed CMSA is designed at $1200 \mathrm{MHz}$ and 3500 MHz. At $1200 \mathrm{MHz}$, various design parameters are, $\mathrm{h}_{1}=2.0$ $\mathrm{cm}, \mathrm{h}_{2}=1.8 \mathrm{~cm}, \mathrm{r}=5.63 \mathrm{~cm}, \mathrm{x}_{\mathrm{f}}=2.55 \mathrm{~cm}, \mathrm{~L}_{\mathrm{p}}=1.75 \mathrm{~cm}$. It gives simulated $\mathrm{BW}$ of $302 \mathrm{MHz}$ whereas measured $\mathrm{BW}$ is $315 \mathrm{MHz}$ as shown in Fig. 7(a). At $3500 \mathrm{MHz}$, various design parameters are, $\mathrm{h}_{1}=0.7 \mathrm{~cm}, \mathrm{~h}_{2}=0.6 \mathrm{~cm}, \mathrm{r}=1.94 \mathrm{~cm}, \mathrm{x}_{\mathrm{f}}=$ $0.87 \mathrm{~cm}, \mathrm{~L}_{\mathrm{p}}=0.6 \mathrm{~cm}$. It gives simulated $\mathrm{BW}$ of $1013 \mathrm{MHz}$ whereas measured BW is $986 \mathrm{MHz}$ as shown in Fig. 7(b). Thus the above parameters can be used to design proximity fed CMSA at any given frequency.

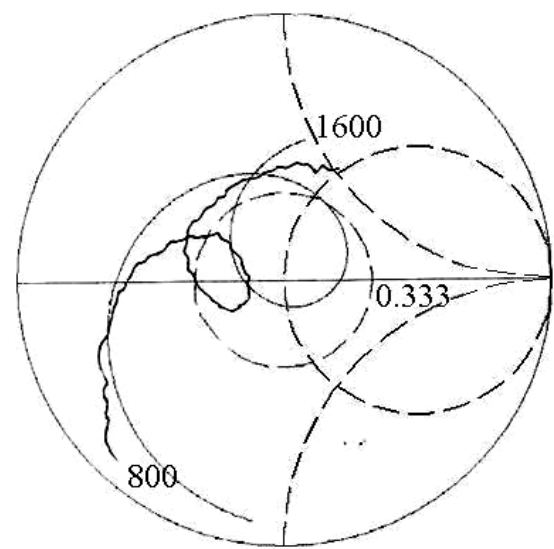

(a)

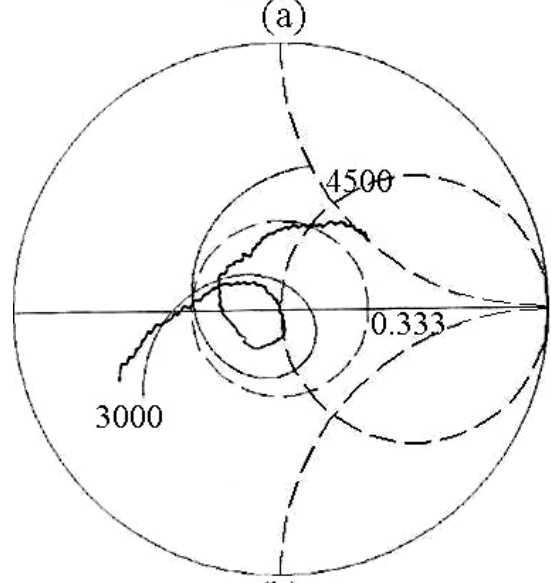

(b)

Fig. 7 Input impedance plots for proximity fed CMSA at (a) $1200 \mathrm{MHz}$ and (b) $3500 \mathrm{MHz},(-)$ simulated, (measured

The proximity fed ETMSA is shown in Fig. 8(a, b). Using equation (5), patch side length ' $\mathrm{S}$ ' is calculated such that it operates in $\mathrm{TM}_{10}$ mode at desired frequency. Using parametric study, proximity fed ETMSA is optimized for different frequencies in $800-8000 \mathrm{MHz}$ frequency band. The results and design parameters for them are tabulated in Table 5 and 6 , respectively. From these values the formulations are obtained as, $\mathrm{X}_{\mathrm{f}}=0.05 \lambda_{0}, 1=0.045 \lambda_{0}$. The proximity fed ETMSA is designed at $800 \mathrm{MHz}$ using these formulation and the results for the same are shown in Fig. 8(c). The simulated and measured BWs are $206 \mathrm{MHz}$ (25.7\%) and $218 \mathrm{MHz}$ (26.7\%), respectively.

$\mathrm{f}_{\mathrm{r}}=\frac{2 \mathrm{c} \sqrt{\mathrm{m}^{2}+\mathrm{mn}+\mathrm{n}^{2}}}{3 \mathrm{~S}_{\mathrm{e}} \pi \sqrt{\varepsilon_{\mathrm{r}}}}$
Table 5: Results for proximity fed ETMSA

\begin{tabular}{|c|c|c|}
\hline Frequency & $\begin{array}{c}\text { Simulated BW, } \\
\text { MHz, \% }\end{array}$ & $\begin{array}{c}\text { Measured BW, } \\
\text { MHz, \% }\end{array}$ \\
\hline $1000 \mathrm{MHz}$ & $348,34.8$ & $342,34.2$ \\
\hline $2000 \mathrm{MHz}$ & 753,37 & $742,36.8$ \\
\hline $3500 \mathrm{MHz}$ & $994,29.1$ & $978,28.8$ \\
\hline
\end{tabular}

Table 6: Design parameters for proximity fed ETMSA

\begin{tabular}{|c|c|c|c|}
\hline Parameter & $1000 \mathrm{MHz}$ & $2000 \mathrm{MHz}$ & $3500 \mathrm{MHz}$ \\
\hline $\mathrm{X}_{\mathrm{f}},(\mathrm{cm})$ & 2.7 & 1.2 & 0.65 \\
\hline $1,(\mathrm{~cm})$ & 1.5 & 0.67 & 0.47 \\
\hline $\mathrm{h}_{1},(\mathrm{~cm})$ & 2.7 & 1.35 & 0.77 \\
\hline
\end{tabular}
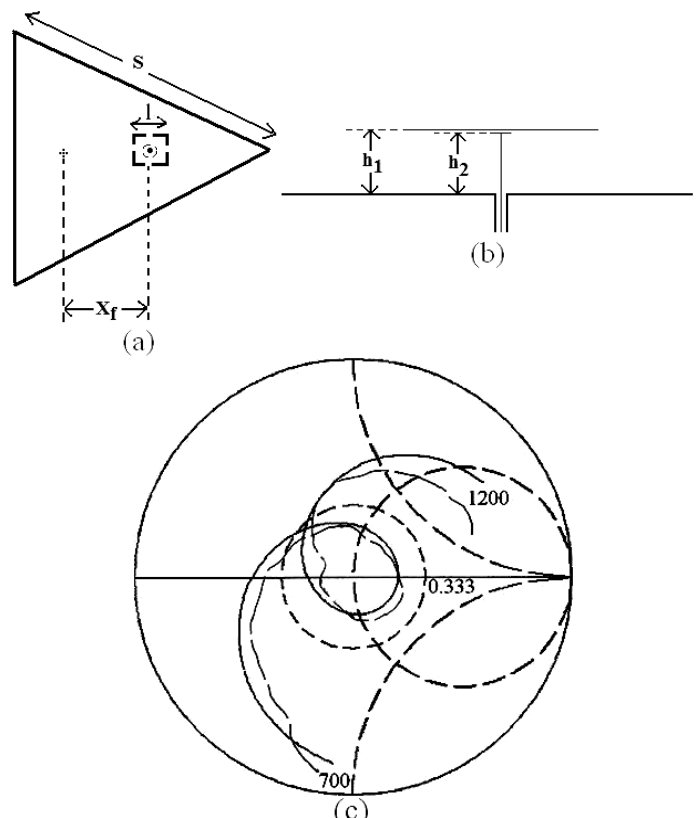

Fig. 8 (a, b) Top and side views and (c) input impedance plots for proximity fed ETMSA at $800 \mathrm{MHz},(-)$ simulated, $(-\longrightarrow)$ measured

\section{PROXIMITY FED SLOT CUT RMSA}

The proximity fed U-slot cut RMSA is shown in Fig. 9(a). The coupling strip is placed inside the slot which is cut in the patch. For slot dimension of $\mathrm{L}_{\mathrm{h}}=4.7 \mathrm{~cm}$ and $\mathrm{L}_{\mathrm{v}}=4.0 \mathrm{~cm}$, coaxially fed U-slot cut RMSA, as shown in Fig. 9(b), is simulated using IE3D software. Its resonance curve plot shows two peaks, as shown in Fig. 9(c). The first one is due to $\mathrm{TM}_{10}$ mode $(841 \mathrm{MHz})$ of the patch and second peak (1190 $\mathrm{MHz}$ ) is due to the U-slot mode. The $\mathrm{TM}_{10}$ mode frequency of RMSA $(\mathrm{L}=13 \mathrm{~cm}$ and $\mathrm{W}=15 \mathrm{~cm}$ ) without $\mathrm{U}$-slot is around $950 \mathrm{MHz}$, which is reduced due to the vertical U-slot length. Using the formulations for $\mathrm{L}_{\mathrm{s}}, \mathrm{L}_{\mathrm{p}}$ and $\mathrm{X}_{\mathrm{f}}$ as given in Table 2, the slot is cut inside the U-slot cut RMSA. Further a coupling strip is placed inside that slot. While using the above formulations $\lambda_{0}$ at the modified $\mathrm{TM}_{10}$ mode frequency due to U-slot is used. The patch is simulated using IE3D software and its resonance curve plot and input impedance locus is shown in Fig. 9(c) and (d), respectively. Since the slot which is cut to include the coupling strip is parallel to the surface currents at $\mathrm{TM}_{10}$ mode, its frequency nearly remains constant. Further it results into the formation of loop due to the $\mathrm{TM}_{10}$ mode inside the VSWR $=2$ circle. The second loop formed is due to mode introduced by U-slot. The variation in its frequency with respect to horizontal U-slot length is shown in Fig. 10(a). By optimizing $\mathrm{L}_{\mathrm{h}}$, the second loop position is optimized inside VSWR $=2$ circle which results into broader 
BW as shown in Fig. 10(b). The simulated BW is $478 \mathrm{MHz}$ $(45.6 \%)$ whereas the measured BW is $470 \mathrm{MHz}(45 \%)$. The antenna have broadside radiation pattern with gain of more than $7 \mathrm{dBi}$ over the complete BW. The fabricated prototype of the configuration is shown in Fig. 10(c).

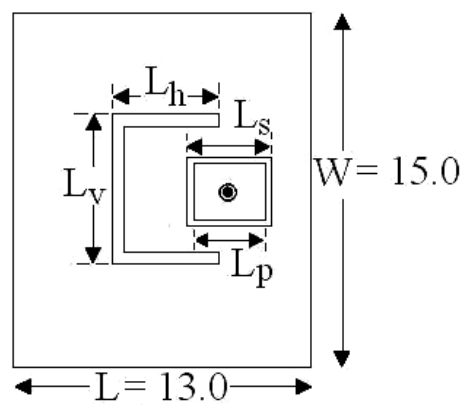

(a)

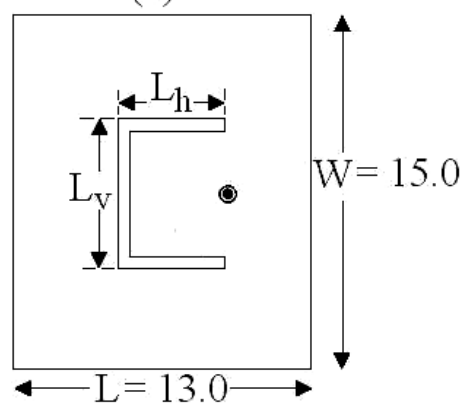

(b)
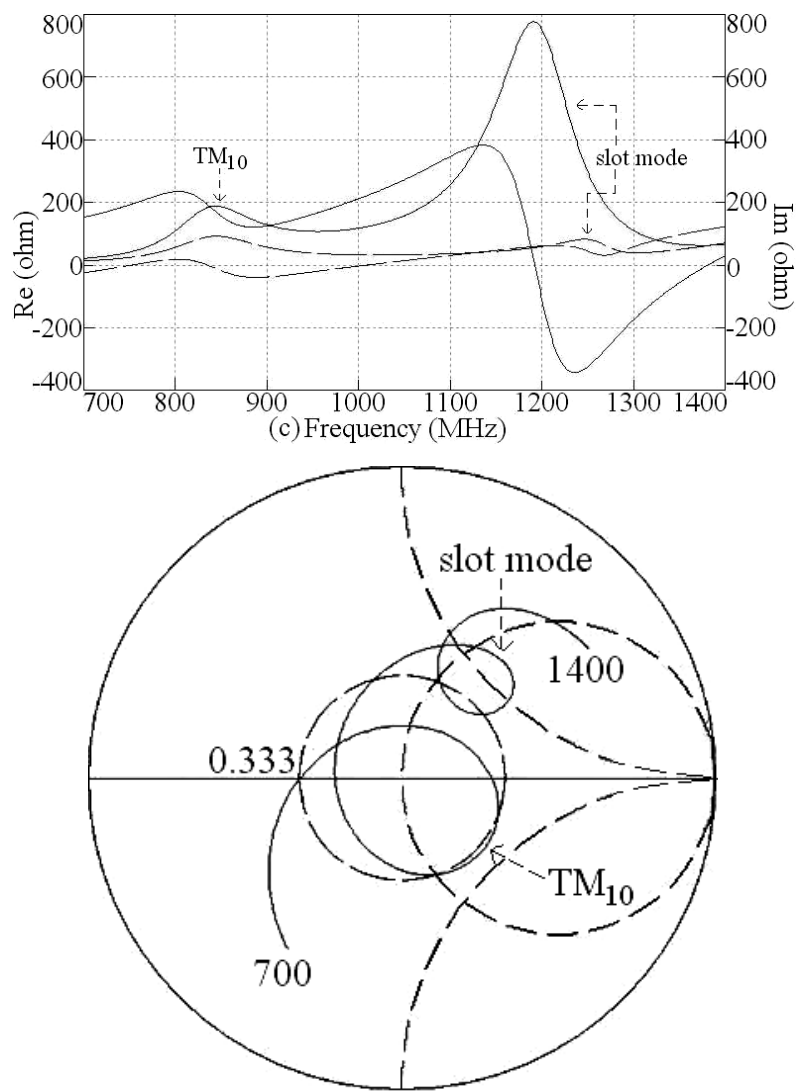

(d)

Fig. 9 (a) Proximity fed U-slot cut RMSA, (b) coaxially fed RMSA, (c) resonance curve plot for (-) U-slot cut RMSA, (- - ) proximity fed U-slot cut RMSA and (d) input impedance plot for proximity fed U-slot cut RMSA
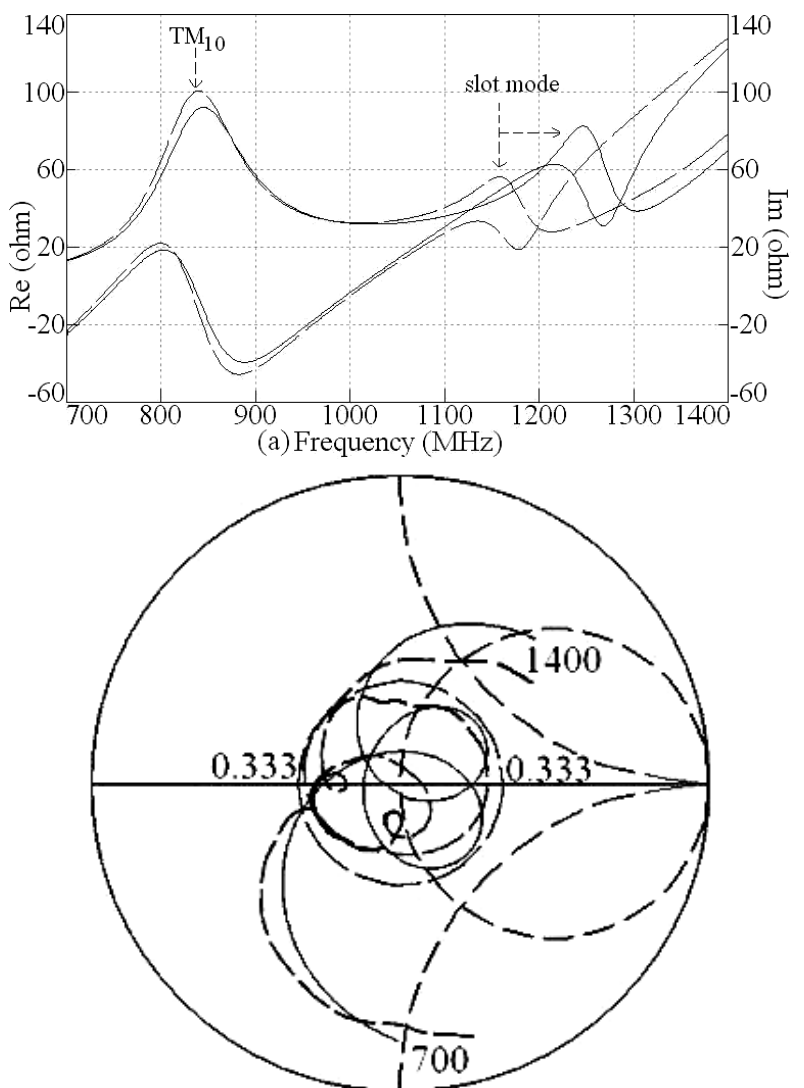

(b)

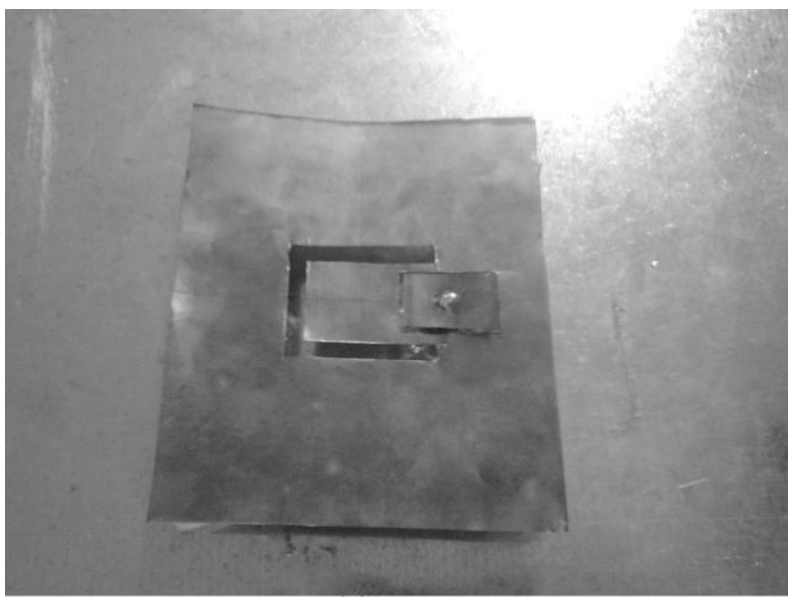

(c)

Fig. 10 (a) Resonance curve plots for $(-) L_{h}=4.7$, ( -) $\mathbf{L}_{\mathbf{h}}=5.1$, (b) input impedance plots, (-) simulated, (- - ) measured and (c) fabricated prototype of proximity fed U-slot cut RMSA 


\section{CONCLUSIONS}

The formulation for edge extension length for thicker substrates over varying frequencies for RMSA and CMSA is proposed. The graphs for the extension length were developed. Using those, RMSAs and CMSAs were redesigned at different frequencies. It gives closer results with the desired frequency with error less than $2 \%$. The formulation for strip dimension and its position below the patch for given substrate thickness in proximity fed RMSA, CMSA and ETMSA is proposed. Using the proposed formulations the RMSAs and CMSAs were re-designed at different frequencies in $800-8000 \mathrm{MHz}$ frequency band. The broadband response with the formation of loop inside the VSWR $=2$ circle is obtained. Further by using the proposed formulations for proximity fed RMSA, a detail design procedure for proximity fed U-slot cut RMSA is presented. It also shows the formation of loop inside the VSWR $=2$ circle with a broader BW of more than $450 \mathrm{MHz}$. Thus the proposed formulations for edge extension length and strip parameters can be used to design RMSA, CMSA or ETMSA at any given frequency and substrate thickness.

\section{REFERENCES}

[1] Kumar, G., and Ray, K. P. 2003, Broadband Microstrip Antennas, First Edition, USA, Artech House

[2] Garg, R., Bhartia, P., Bahl, I., and Ittipiboon, A., Microstrip Antenna Design Handbook, 2001, Artech House, USA
[3] Cock, R. T., and Christodoulou, C. G. 1987. Design of a two layer capacitively coupled, microstrip patch antenna element for broadband applications, IEEE Antennas Propag. Soc. Int. Symp. Dig., vol. 2, 936-939.

[4] Huynh, T., and Lee, K. F. 1995. Single-Layer SinglePatch Wideband Microstrip Antenna, Electronics Letters, vol. 31, no. 16, (August 1995), 1310-1312.

[5] Lee, K. F., Yang, S. L. S., Kishk, A. A., and Luk, K. M. 2010. The Versatile U-slot Patch, IEEE Antennas \& Propagation Magazine, vol. 52, no. 1, (February 2010), $71-88$

[6] Guo, Y. X., Luk, K. M., Lee, K. F., and Chow, Y. L. 1998. Double U-slot Rectangular Patch Antenna, Electronics Letters, vol. 34, 1805 - 1806

[7] Sharma, S. K., and Shafai, L. 2009. Performance of a Novel $\Psi$-Shaped Microstrip Patch Antenna with Wide Bandwidth, IEEE Antennas \& Wireless Propagation Letters, vol. 8, $468-471$.

[8] Wong, K. L. 2002. Compact and Broadband Microstrip Antennas, John Wiley \& sons, Inc., New York, USA

[9] Deshmukh, Amit A., Joshi, Apurva A., and Tirodkar, T., Broadband slot cut gap-coupled proximity fed Eshaped Microstrip Antenna, International Journal of Computer Application, vol. 68, no. 17, April 2013, 15 18

[10] IE3D 12.1, 2004. Zeland Software, Freemont, USA

[11] Balanis, C. A., Antenn Theory: analysis and design, $2^{\text {nd }}$ edition, John Wiley \& Sons Ltd. 